\title{
Evaluation of financial outcomes under a value-based payment program for community pharmacies
}

William R Doucette, PhD; Russell DeVolder, PharmD; and Thomas Heggen, BS

\section{What is already known about this subject}

- Value-based payment models, which could help improve care coordination and transition of care, have been promoted to support quality of care and reduce waste.

- A community pharmacy that closely monitors patient's medication therapy showed lower costs of care in a pilot study.

- There has been limited evidence on the outcomes of value-based pharmacy programs (VBPPs).

\section{ABSTRACT}

BACKGROUND: Value-based payment models have been shown to limit health care spending and waste while improving quality of care. Evidence from value-based pharmacy programs (VBPPs) is needed to guide the use of these mechanisms in health care.

OBJECTIVE: To evaluate financial outcomes of a VBPP implemented in 73 community pharmacies for about 40,000 commercial beneficiaries of Wellmark, Inc.

METHODS: Beneficiaries were attributed to pharmacies based on the number of prescriptions dispensed. The VBPP paid community pharmacies a per capita payment based on their performance on a set of metrics to deliver care the pharmacists believed was necessary to optimize the beneficiaries' medication therapy and associated outcomes. Financial

\section{What this study adds}

- A value-based payment program of providing capitated payments to community pharmacies offering enhanced clinical services significantly and reduced total cost of care in a commercial population with one or more chronic conditions.

- A VBPP showed no statistical difference in hospital admission rates.

- Similarly, the difference in emergency department (ED) visit rate did not reach statistical significance. outcome variables were analyzed for the calendar year of 2018, including total cost of care, hospital admissions, and emergency department (ED) visits. Hospital admissions and ED visits were identified through claims data. Generalized linear models were used to test the effect of the VBPP on each of the outcome variables by comparing outcomes for beneficiaries attributed to the pharmacies participating in the VBPP (73 pharmacies) to Wellmark's beneficiaries attributed to nonparticipating pharmacies (847 pharmacies). Independent variables used in the models to control for possible confounding included beneficiary demographics and complexity scores, region code, accountable care organization (ACO) attribution, beneficiary product type (health maintenance organization (HMO), preferred provider organization (PPO), and several disease indicator variables.

RESULTS: Analyses showed in 2018 that the per beneficiary per month total costs of

\section{Author affiliations \\ William R Doucette, PhD, University of lowa, Pharmacy Practice and Science, lowa City, IA. Russell DeVolder, PharmD, and Thomas Heggen, BS, Wellmark Blue Cross Blue Shield, Des Moines, IA.}

AUTHOR CORRESPONDENCE: William R Doucette, 319.335.8786; william-doucette@uiowa.edu

J Manag Care Spec Pharm. 2021;27(9):1198-208

Copyright (C)2021, Academy of Managed Care Pharmacy. All rights reserved.

care for the beneficiaries going to the VBPP pharmacies $(\mathrm{N}=15,463)$ was $\$ 30.48(4.5 \%$; $95 \% \mathrm{Cl}=-6.2 \%$ to $-2.7 \%$ ) lower than that of the non-VBPP group $(\mathrm{N}=140,717)$. The hospital admission rate for the VBPP group was $5.1 \%$ lower but was not statistically significant $(95 \% \mathrm{Cl}=-12.9 \%$ to $3.3 \%)$. Similarly, the ED visit rate for the VBPP group was $2.1 \%$ lower than the non-VBPP group but did not reach statistical significance $(95 \% \mathrm{Cl}=-8.6 \%$ to $3.3 \%$ ).

CONCLUSIONS: With the growing need for solutions to improve quality of care while reducing health care costs and waste, a value-based payment program using performance-determined capitated payments to community pharmacies offering enhanced clinical services significantly reduced total costs of care in a commercial population with one or more chronic conditions. Future work with this promising model is encouraged. 
There has been growing interest in identifying and removing waste from health care in the United States. ${ }^{1,2}$ Those initial studies of health care waste, which estimated health care waste at $\$ 760-\$ 935$ billion, have recognized health care waste can occur in a variety of ways, including failure of care delivery, care coordination, providing low-value care, and administrative complexity. ${ }^{1}$ For the millions of patients with multiple chronic conditions who tend to receive care from several providers, failure of care coordination and administrative complexity can be especially costly. For example, coordination of care can be inhibited when not all providers can access patient records held in other providers' electronic medical records (EMRs), resulting in increased incidence of overtreatment and medical errors. ${ }^{3}$ Transition of care can also be problematic for many patients since communication errors can easily occur. ${ }^{4}$ Further, administrative rules often create barriers to enhanced care coordination and timely delivery of care. ${ }^{5,6}$ Value-based payment models could help improve care coordination and transition of care and have been promoted by policies of the Centers for Medicare and Medicaid Services (CMS) to support quality of care and reduce waste. ${ }^{7}$

Two early value-based payment demonstration projects conducted by CMS evaluated pay-for-performance approaches: the Physician Group Practice Demonstration and the Premier Hospital Quality Incentive Demonstration. Though both demonstrations did not show effects on health care expenditures, lessons learned helped shape current value-based payment models. ${ }^{8}$ More recently, CMS has sponsored multiple value-based payment programs for hospitals, including the Hospital Value-Based Purchasing Program, the Hospital Readmission Reduction Program, and the Hospital-Acquired Condition Reduction Program. ${ }^{8}$ Similarly, in response to the Medicare Access and the State Children's Health Insurance Program Reauthorization Act of 2015 (MACRA), CMS has spurred the development of value-based payment models for physicians and other eligible clinicians, including the Merit-Based Incentive Payment System and Alternative Payment Models. ${ }^{7,9}$ These MACRA programs primarily assess physician performance on quality of care and cost/utilization measures.

Despite the growth of value-based payment programs for other providers, value-based payment models focused on pharmacies are less common. Many patients with chronic conditions take multiple medications, often prescribed by different providers. Community pharmacists are positioned to monitor the effects of medication therapy and improve care coordination with providers and patients. ${ }^{10}$ In addition, pharmacists have assumed a primary role in helping patients adhere to medication therapy. Pharmacists can be the target of value-based payment programs that pay them to help optimize medication use and outcomes, which could reduce health care waste.

One pharmacy value-based payment program has been a pay-for-performance model operated by Inland Empire Health Plan, a nonprofit Medicare and Medicaid health plan in southern California. The metrics of this program focused primarily on improving medication adherence. Pharmacy performance in the Inland program has been associated with Medicare Part D plan star ratings, but direct links to beneficiary outcomes have not been reported.11 The Pennsylvania Project, another pharmacy pay-for-performance model, involved pharmacists at a large pharmacy chain providing brief interventions to improve patients' medication adherence. ${ }^{12}$ Those interventions significantly raised medication adherence rates for 5 classes of chronic medications compared to a control group. In addition, the treatment subgroups with patients taking oral diabetes agents (\$341 lower total costs) and taking statins for cholesterol management (\$241 lower total costs) had lower annual total health care costs compared with similar patient subgroups in the control group. These 2 programs showed community pharmacists could affect medication adherence and health care waste and costs by working closely with their patients in Medicare and Medicaid health plans. However, there is limited evidence about how community pharmacists delivering enhanced services could affect health care costs under a commercial value-based payment approach.

To explore the impact community pharmacists could have on total health care costs, an insurer worked directly with an innovative community pharmacy on a pilot study in a commercial population of patients. During that pilot, the pharmacists delivered an enhanced service entailing continuous medication monitoring in which they identified, resolved, and documented medication-related problems at the time of dispensing (eg, medication nonadherence, adverse drug reactions, and duplication of therapy). ${ }^{13}$ Analysis of costs under that approach showed beneficiaries who went only to the study pharmacy had significantly lower total cost of care (\$298 per person per month) than those who did not go to that pharmacy. ${ }^{13}$ To further explore the opportunity of developing a network of highperforming pharmacies that could improve medication use while reducing total cost of care, Wellmark Blue Cross Blue Shield developed a value-based pharmacy program (VBPP) for its commercial plans. The purpose of this paper is to report on the financial performance of the VBPP from Wellmark's perspective. 


\begin{tabular}{|c|c|c|}
\hline Domain & Metric & Performance calculation \\
\hline $\begin{array}{l}\text { Chronic disease } \\
\text { management }\end{array}$ & $\begin{array}{l}\text { Asthma controller medication } \\
\text { adherence }\end{array}$ & $\begin{array}{l}\text { Percentage of attributed members with persistent asthma with asthma } \\
\text { controller medication adherence greater than } 75 \%\end{array}$ \\
\hline $\begin{array}{l}\text { Chronic disease } \\
\text { management }\end{array}$ & Asthma medication ratio & $\begin{array}{l}\text { Percentage of attributed members with persistent asthma with a ratio of } \\
\text { controller to acute medications dispensed greater than } 0.5\end{array}$ \\
\hline $\begin{array}{l}\text { Chronic disease } \\
\text { management }\end{array}$ & ACEi/ARB medication adherence & $\begin{array}{l}\text { Percentage of attributed members with diabetes with an ACEI/ARB adherence } \\
\text { greater than } 80 \%\end{array}$ \\
\hline $\begin{array}{l}\text { Chronic disease } \\
\text { management }\end{array}$ & $\begin{array}{l}\text { Non-insulin diabetes medication } \\
\text { adherence }\end{array}$ & $\begin{array}{l}\text { Percentage of attributed members with diabetes with non-insulin diabetes } \\
\text { medication adherence greater than } 80 \%\end{array}$ \\
\hline $\begin{array}{l}\text { Chronic disease } \\
\text { management }\end{array}$ & Diabetic Alc documented* & $\begin{array}{l}\text { Percentage of attributed members with diabetes with an Alc reported in } \\
\text { performance year }\end{array}$ \\
\hline $\begin{array}{l}\text { Chronic disease } \\
\text { management }\end{array}$ & Diabetic Alc control & $\begin{array}{l}\text { Percentage of attributed members with diabetes with most recent Alc less } \\
\text { than } 7.5 \text { in Performance Year }\end{array}$ \\
\hline $\begin{array}{l}\text { Chronic disease } \\
\text { management }\end{array}$ & $\begin{array}{l}\text { Diabetic blood pressure } \\
\text { documented }\end{array}$ & $\begin{array}{l}\text { Percentage of attributed members with diabetes with a blood pressure } \\
\text { reported in performance year }\end{array}$ \\
\hline $\begin{array}{l}\text { Chronic disease } \\
\text { management }\end{array}$ & Diabetic blood pressure control & $\begin{array}{l}\text { Percentage of attributed members with diabetes with most recent blood } \\
\text { pressure of less than } 140 / 90 \text { in performance year }\end{array}$ \\
\hline $\begin{array}{l}\text { Chronic disease } \\
\text { management }\end{array}$ & Statin adherence & Percentage of attributed members with statin adherence greater than $80 \%$ \\
\hline $\begin{array}{l}\text { Chronic disease } \\
\text { management }\end{array}$ & Statin intensity: Moderate & $\begin{array}{l}\text { Percentage of attributed members taking a moderate-intensity statin based on } \\
\text { guideline recommendations }\end{array}$ \\
\hline $\begin{array}{l}\text { Chronic disease } \\
\text { management }\end{array}$ & Statin intensity: High & $\begin{array}{l}\text { Percentage of attributed members taking a high-intensity statin based on } \\
\text { guideline recommendations }\end{array}$ \\
\hline $\begin{array}{l}\text { Chronic disease } \\
\text { management }\end{array}$ & $\begin{array}{l}\text { Depression acute treatment } \\
\text { adherence }\end{array}$ & $\begin{array}{l}\text { Percentage of attributed members with newly diagnosed/treated depression } \\
\text { who remained on an antidepressant medication for } 12 \text { weeks following the } \\
\text { prescription start date }\end{array}$ \\
\hline $\begin{array}{l}\text { Chronic disease } \\
\text { management }\end{array}$ & $\begin{array}{l}\text { Depression continuation treatment } \\
\text { adherence }\end{array}$ & $\begin{array}{l}\text { Percentage of attributed members with newly diagnosed/treated depression } \\
\text { with at least } 6 \text { months of continuous antidepressant medication treatment } \\
\text { following prescription start date }\end{array}$ \\
\hline $\begin{array}{l}\text { Chronic disease } \\
\text { management }\end{array}$ & $\begin{array}{l}\text { Depression Questionnaire } \\
\text { completion* }^{\star}\end{array}$ & $\begin{array}{l}\text { Percentage of members with newly diagnosed/treated depression who } \\
\text { completed a PHQ-9 in performance year }\end{array}$ \\
\hline $\begin{array}{l}\text { Chronic disease } \\
\text { management }\end{array}$ & Depression outcomes* & $\begin{array}{l}\text { Percentage of attributed members with newly diagnosed/treated depression } \\
\text { who experience remission (as measured by PHQ-9) at } 6 \text { months following the } \\
\text { prescription start date in performance year }\end{array}$ \\
\hline $\begin{array}{l}\text { Potentially preventable } \\
\text { ED visits }\end{array}$ & $\begin{array}{l}\text { Potentially preventable emergency } \\
\text { department visits variance }\end{array}$ & $\begin{array}{l}\text { Difference between Wellmark Pharmacy Network PPV rate and risk-adjusted } \\
\text { actual PPV rate }\end{array}$ \\
\hline $\begin{array}{l}\text { Potentially preventable } \\
\text { admissions }\end{array}$ & $\begin{array}{l}\text { Potentially preventable admissions } \\
\text { variance }\end{array}$ & $\begin{array}{l}\text { Difference between Wellmark Pharmacy Network PPA rate and risk-adjusted } \\
\text { actual PPA rate }\end{array}$ \\
\hline Total cost of care & Total cost of care PMPM variance & $\begin{array}{l}\text { Difference between Wellmark Pharmacy Network TCC PMPM and risk-adjusted } \\
\text { actual PMPM }\end{array}$ \\
\hline
\end{tabular}

$A 1 C=$ hemoglobin $A 1 c ; A C E$ = angiotensin-converting enzyme inhibitors; $A R B=$ angiotensin receptor blockers; $P H Q-9=$ Patient Health Questionnaire-9; $P P A=$ potentially preventable admission; $P M P M=$ per beneficiary per month; $P P V=$ potentially preventable visit; $T C C=$ total cost of care.

\section{VBPP}

The VBPP launched in July of 2017 with 62 community pharmacies, which was increased to 73 in 2018, all located in Iowa. A total of 16 different pharmacy organizations made up the 73 participating pharmacies, including regional chains and independent pharmacies. Wellmark worked with pharmacy leaders in the state to develop 5 criteria for participating pharmacies: (1) offers multiple clinical services (eg, yearround immunization program, comprehensive medication reviews, and medication synchronization appointments); (2) formally documents services delivered and communicates information to beneficiary's providers; (3) developed 


\section{TABLE 2} Description of Beneficiaries by Study Group, January-December 2018

\begin{tabular}{l|c|c}
\hline \multicolumn{1}{c|}{ Characteristic } & $\begin{array}{c}\text { Beneficiaries } \\
\text { in value-based } \\
\text { pharmacy } \\
\text { program } \\
\mathbf{N}=\mathbf{1 5 , 4 6 3}\end{array}$ & $\begin{array}{c}\text { Beneficiaries } \\
\text { not in value- } \\
\text { based } \\
\text { pharmacy } \\
\text { program } \\
\mathbf{N}=\mathbf{1 4 0 , 7 1 7}\end{array}$ \\
\hline Sex (\% female) & 55.0 & 56.3 \\
\hline Age (mean \& SD) & $48.6(16.1)$ & $48.2(15.9)$ \\
\hline Number of chronic medications (mean \& SD) & $3.0(2.5)$ & $2.9(2.5)$ \\
\hline Chronic conditions (\%) & \multicolumn{1}{|c}{} \\
\hline Coronary artery disease & 5.1 & 4.9 \\
\hline Diabetes & 12.4 & 13.1 \\
\hline Depression & 19.6 & 19.5 \\
\hline Asthma & 8.2 & 8.4 \\
\hline Geographic region of IA (\%) & & \\
\hline Northwest & 5.5 & 13.2 \\
\hline Southwest & 7.7 & 6.0 \\
\hline Central & 49.4 & 35.1 \\
\hline Northeast & 15.2 & 21.5 \\
\hline Southeast & 22.2 & 24.1 \\
\hline 3M Clinical Risk Group - medical risk weight (mean \& SD) & $1.98(3.26)$ & $1.93(3.11)$ \\
\hline 3M Clinical Risk Group - pharmacy risk weight (mean \& SD) & $2.32(3.95)$ & $2.27(3.71)$ \\
\hline Accountable care organization membership (\%) & 69.4 & 65.3 \\
\hline Preferred provider organization membership (\%) & 55.0 & 59.4 \\
\hline
\end{tabular}

awellmark data.

Note: Clinical Risk Group (3M) is a commercial categorical clinical model that uses claims data to assign each beneficiary to a single mutually exclusive risk category. The Clinical Risk Group values were calculated from 2017 data.

a service plan based on communityspecific needs; (4) established a formal immunization protocol and/or a collaborative practice agreement; and (5) performs ongoing pharmacist training. The intent was to involve pharmacies that were actively delivering services likely to support care coordination that were targeted at the needs of their local communities. For the VBPP, beneficiaries with at least one chronic condition were attributed to pharmacies that dispensed the most prescription medications to them during a previous 12-month period. There were about 40,000 beneficiaries attributed to pharmacies that participated in the VBPP. The VBPP based payments on 18 metrics developed by a joint council of health plan, community pharmacists and state pharmacy association personnel (Table 1). The metrics assessed pharmacy performance on chronic disease medication management, potentially preventable emergency department (ED) visits, potentially preventable admissions, and total cost of care (medical and drug costs). The chronic disease metrics focused on asthma, diabetes, cardiovascular (hypertension, high cholesterol), and depression. To support pharmacist monitoring, performance metrics were calculated monthly for each pharmacy from a rolling 12 months of claims data and from data uploaded by participating pharmacies through a web-based VBPP dashboard. These monthly performance reports were made available to the pharmacies via the VBPP dashboard.

The VBPP payments were separate from dispensing payments and were provided directly by Wellmark (ie, not through a pharmacy benefits manager). Per capita payment amounts were calculated annually based on 3 relative performance components: (1) in relation to the median performance of all pharmacies in Wellmark's network (VBPP and non-VBPP), (2) selfcomparison over time (ie, current year to previous year), and (3) to only the VBPP participating pharmacies (ie, compared to the 85th percentile of all pharmacies participating in the VBPP). Using points earned from the 18 metrics, a composite performance score was calculated and used to determine a per capita (per beneficiary per month (PBPM) payment for beneficiaries attributed to each participating pharmacy organization. The total cost of care, emergency department visits, and hospital admission metrics were summed to $58 \%$ of the overall composite score. Since capitation-based payments were used, no claims were submitted by the pharmacies for services performed for beneficiaries in the VBPP. Clinical documentation of services provided to attributed beneficiaries was auditable by Wellmark. The specific objectives of this study were to describe the VBPP and analyze the effects of the VBPP on financial outcomes from a commercial insurer perspective. 


\section{FIGURE 1 Effects of Value-Based Pharmacy Program on Costs and Utilization}

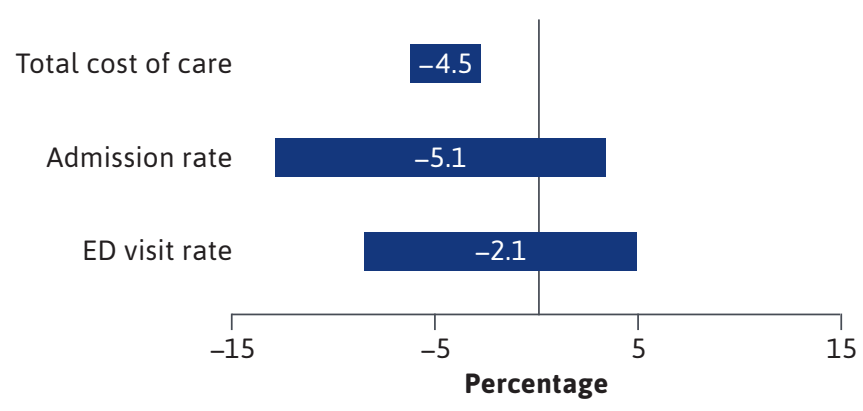

Note: The differences shown are for services delivered in calendar year 2018. The calculated $95 \%$ confidence intervals were: total cost of care $-6.2 \%$ to $-2.7 \%$ ( $-\$ 46.30$ to $-\$ 19.69$ PMPM), admission rate $-12.9 \%$ to $3.3 \%$ and $E D$ visit rate $-8.6 \%$ to $3.3 \%$.

$E D=$ emergency department; $P M P M=$ per beneficiary per month.

\section{Methods}

For the primary evaluation of the VBPP's effects on financial outcomes, program data for calendar year 2018 were collected and analyzed. These data included hospital, medical, and pharmacy claims. Beneficiaries included in the analyses had at least one of any chronic conditions, continuous insurance coverage for all of 2017 and 2018, and continuous attribution to a single pharmacy in Wellmark's pharmacy network in 2017 and 2018. Excluded beneficiaries had a diagnosis of a malignancy or pregnancy. Financial outcome variables were analyzed for the calendar year of 2018, including total cost of care, hospital admissions, and ED visits. For total cost of care, PBPM amounts were calculated for 2 groups of beneficiaries who met the inclusion/exclusion criteria: those attributed to the pharmacies participating in the VBPP and those attributed to all other pharmacies in Wellmark's pharmacy networks in Iowa.

In addition to the claims data for 2018, other variables were measured using data from Wellmark. Beneficiary demographic variables included gender and age. Also, presence of the 4 target chronic conditions was determined for each beneficiary using the International Classification of Diseases, Tenth Revision codes. The number of medications for chronic conditions was also calculated. The geographic region for beneficiaries was assigned as 1 of 5 regions served by Wellmark. Further, beneficiary membership in an accountable care organization (ACO), health maintenance organization (HMO), or preferred provider organization
(PPO) were collected. From a vendor, 3M Clinical Risk Group (CRG) adjustment figures and health status also were obtained. All data were from 2018, except the CRG adjustments that were from 2017.

\section{VBPP OUTCOMES}

Total cost of care amounts included in the analyses were aggregated actual payments for care received by all attributed beneficiaries. Total costs, PBPM amounts, were calculated by totaling all plan and beneficiary direct paid costs for 2018 and then dividing by 12. Hospital admissions and ED visits were identified through claims data. All-cause inpatient admissions and ED visits were included in the data.

\section{STATISTICAL ANALYSES}

Generalized linear models were run to test the effect of the VBPP on each of the outcome variables by comparing outcomes for beneficiaries attributed to the pharmacies participating in the VBPP (73 pharmacies) to Wellmark's beneficiaries attributed to nonparticipating pharmacies (847 pharmacies). Independent variables used in the models to control for possible confounding included beneficiary age, beneficiary gender, beneficiary health status, number of chronic medications, number of nonchronic medications, CRG medical risk weight, CRG pharmacy risk weight, CRG hospital admission weight, CRG ED visit weight, region code, ACO attribution, beneficiary product type (HMO, PPO), coronary artery disease indicator, diabetes indicator, depression indicator, and asthma indicator. To best fit the distributions of the outcome variables, total cost of care models were run as negative binomial, whereas the hospital admission and ED visit count variables were run as Poisson models. In addition, the differences in PBPM total costs of the VBPP beneficiaries and the non-VBPP beneficiaries for a baseline year (2016), the first (partial) year of the VBPP (2017), and the first complete year of the program (2018) were calculated and plotted.

Under the VBPP, no claims were filed nor were the participating pharmacies required to perform specific services, but they reported performing a mix of care activities. ${ }^{17}$ These actions included multiple activities related to medication adherence, such as tracking adherence at time of dispensing, using medication synchronization with pharmacist-patient interactions, providing medication adherence packaging, and delivering adherence interventions. The pharmacists reported regularly using the VBPP dashboard to identify beneficiaries to target specific patients (eg, beneficiaries with asthma, beneficiaries with moderate to high CRG values). The VBPP pharmacies also 


\section{TABLE 3}

\begin{tabular}{|c|c|c|c|}
\hline Parameter & Estimate & SE & $\begin{array}{l}\text { Wald } \\
\text { chi-square }\end{array}$ \\
\hline Non-VBPP pharmacy & 0.046 & 0.0093 & $24.57^{d}$ \\
\hline Wellmark ACO indicator (not in ACO) & 0.0405 & 0.006 & $45.87^{d}$ \\
\hline Health status - nonuser & -0.9000 & 0.5410 & $2.76^{\mathrm{a}}$ \\
\hline Health status - healthy & -0.3030 & 0.0295 & $105.41^{d}$ \\
\hline Health status - acute & -0.1180 & 0.0375 & $9.87 c$ \\
\hline Health status - minor chronic & -0.0240 & 0.0262 & 0.84 \\
\hline Health status - single chronic & 0.1470 & 0.0251 & $34.24^{\mathrm{d}}$ \\
\hline Health status -double chronic & 0.2340 & 0.0235 & $99.03^{d}$ \\
\hline Health status - catastrophic & 0.5720 & 0.0500 & $131.07^{d}$ \\
\hline Region - northwest IA & 0.0404 & 0.0094 & $18.56^{\mathrm{d}}$ \\
\hline Region - southwest IA & 0.0336 & 0.0122 & $7.63^{c}$ \\
\hline Region - northeast IA & 0.0205 & 0.0073 & $7.84^{c}$ \\
\hline Region - southeast IA & 0.0225 & 0.0077 & $8.59^{c}$ \\
\hline Number of chronic drugs & 0.0718 & 0.0014 & $2,530.70^{d}$ \\
\hline Number of nonchronic drugs & 0.0778 & 0.0011 & $4,777.50^{d}$ \\
\hline $\begin{array}{l}\text { Clinical Risk Group 3M - medical risk weight } \\
\text { value }\end{array}$ & 0.0665 & 0.0014 & $2,114.40^{d}$ \\
\hline $\begin{array}{l}\text { Clinical Risk Group3M - pharmacy risk } \\
\text { weight value }\end{array}$ & 0.0694 & 0.0012 & $3,102.40^{d}$ \\
\hline Wellmark PPO indicator (yes in PPO) & 0.0878 & 0.0059 & $221.50^{d}$ \\
\hline Intercept & 7.8920 & 0.0287 & $75,473.60^{d}$ \\
\hline
\end{tabular}

Note: Comparison groups include VBPP pharmacy, inside of ACO, health status - triple chronic, region central lowa, and not in PPO.

$a^{a}<0.10$.

${ }^{b}<0.05$.

${ }^{c}<0.01$.

${ }^{d}<0.001$.

Total $N=155,864 ; A I C=3,031,155$

$A C O=$ accountable care association; $A I C=$ Akaike information criterion; $P P O=$ preferred provider organization; $\mathrm{VBPP}=$ value-based pharmacy program.

stated they worked to collect lab/ clinical data (eg, hemoglobin A1c) to monitor a patient's progress. Also, over the time of the VBPP, the pharmacists noted they documented more care activities (eg, taking blood pressure, discussing medication adherence, and contacting a provider about a medication change). This study was considered exempt by the University of Iowa Human Subjects Office.

\section{Results}

For the analyses, a total of 15,463 beneficiaries were included in the VBPP group, and 140,717 beneficiaries were included in the non-VBPP comparison group. The 2 groups were similar on gender (over $50 \%$ female), age (mean about 48 years), number of chronic medications (mean about 3 medications), percent with target conditions, and CRG scores. The VBPP group had a slightly greater percent in Wellmark's $\mathrm{ACO}$ and lower membership in a PPO (Table 2). There were some differences geographically, which related to the locations of the participating pharmacies.

As shown in Figure 1, the PBPM total cost of care for the VBPP group was $\$ 30.48$ (4.5\%) lower than that of the non-VBPP and statistically significant (95\% CI $=-6.2 \%$ to $-2.7 \%)$. The hospital admission rate for the VBPP group was 5.1\% lower but was not statistically significant $(95 \% \mathrm{CI}=-12.9 \%$ to $3.3 \%)$. Similarly, the ED visit rate for the VBPP group was 2.1\% lower than the non-VBPP group but did not reach statistical significance $(95 \% \mathrm{CI}=-8.6 \%$ to $3.3 \%)$. The coefficients for these analyses can be found in Tables 3-5. In disease specific analyses, the VBPP total costs for heart disease were $12.9 \%$ lower, total costs for depression were $5.9 \%$ lower, total costs for diabetes were $4.3 \%$ lower, and total costs for asthma were $0.4 \%$ higher. These differences were statistically significant for heart disease and depression.

The longitudinal plot of the influence of the VBPP on total cost of care showed a growth in the reduction of costs from 2016 through 2018. In 2016 the VBPP group had a total cost of care that was $0.8 \%$ lower than the comparison group, which increased to $2.8 \%$ lower in 2017 and to $4.5 \%$ lower in 2018. No VBPP was in place during 2016, and it launched in July 2017, making that a transition year. The 2018 numbers represent a full year of the VBPP after start-up in 2017.

\section{Discussion}

This VBPP has promise as a value-based payment program that incentivizes community pharmacies to provide enhanced services via a pay-for-performance, per capita structure. This VBPP focused on community pharmacists improving their care in response 


\section{TABLE 4 Regression Results for Hospital Admissions} (graphed in Figure 1)

\begin{tabular}{l|c|c|c}
\hline \multicolumn{1}{c|}{ Parameter } & Estimate & SE & $\begin{array}{c}\text { Wald } \\
\text { chi-square }\end{array}$ \\
\hline Non-VBPP pharmacy & 0.0527 & 0.0433 & 1.48 \\
\hline Wellmark ACO indicator (not in ACO) & 0.0512 & 0.0289 & $3.13^{\mathrm{a}}$ \\
\hline Urban location (no) & 0.0167 & 0.0282 & 0.35 \\
\hline Gender (female) & 0.2420 & 0.0269 & $80.99^{\mathrm{d}}$ \\
\hline Number of unique drugs & 0.0659 & 0.0033 & $409.21^{\mathrm{d}}$ \\
\hline Number of prescriptions dispensed & 0.0199 & 0.0064 & $9.78^{\mathrm{c}}$ \\
\hline Clinical Risk Group 3M- admission risk & 0.0372 & 0.0008 & $1,954.50^{\mathrm{d}}$ \\
\hline weight value & -0.2020 & 0.0412 & $24.07^{\mathrm{d}}$ \\
\hline Coronary artery disease indicator (no) & -0.1433 & 0.0301 & $22.70^{\mathrm{d}}$ \\
\hline Depression indicator (no) & -0.1350 & 0.0334 & $16.38^{\mathrm{d}}$ \\
\hline Diabetes indicator (no) & 0.0491 & 0.0427 & 1.32 \\
\hline Asthma indicator (no) & -0.0272 & 0.0267 & 1.03 \\
\hline Wellmark PPO indicator (yes in PPO) & -2.9670 & 0.0882 & $1,132.40^{\mathrm{d}}$ \\
\hline Intercept & & & \\
\hline
\end{tabular}

Note: Comparison groups include VBPP pharmacy, ACO indicator (yes), urban indicator (yes), gender (male), coronary artery disease indicator (yes), depression indicator (yes), diabetes indicator (yes), asthma indicator (yes), and not in PPO.

$a_{<}<0.10$.

${ }^{b}<0.05$.

${ }^{c}<0.01$

${ }^{d}<0.001$

Total $\mathrm{N}=155,864 ; \mathrm{AIC}=81,645.9$

$A C O=$ accountable care association; $A I C=$ Akaike information criterion; $E D=$ emergency department: $P P O=$ preferred provider organization; $V B P P=$ value-based pharmacy program.

to performance metrics rather than focusing on reduced cost sharing targeted at patients, as used in many previously studied value-based payment programs..$^{14,15}$ Those studies of value-based payment programs tended to show some improvement in medication adherence but little net improvement in total costs..$^{14,15}$ Another contrast here is that the financial outcomes were calculated for all attributed beneficiaries and not only those with a targeted disease state. This broader program showed significantly lower total cost of care $(4.5 \%$, -\$30.48 PBPM), compared to beneficiaries not attributed to the VBPP pharmacies. Assuming similar results and using the average per beneficiary cost of total annual commercial health care expenditures from $2018(\$ 5,892)$, a payer with 100,000 beneficiaries with at least one chronic condition could realize a savings of \$26.5 million for a 1-year period. ${ }^{16}$ The pharmacists in the VBPP were able to work with a diverse, yet familiar, group of patients with chronic conditions. It is unclear how readily these results would apply to other pharmacies and patient groups. Though some program metrics focused on 4 chronic conditions, the financial metrics analyzed here included all attributed beneficiaries regardless of presence/absence of 1 or more of the 4 chronic conditions. This approach allowed the pharmacists to target some patients but also limited the benefits of focusing on only a small subgroup of patients (ie, hot spotting). This capitated value-based payment model has promise in that it successfully incentivized the participating pharmacies to provide services to a mix of beneficiaries that generated considerable savings in health care spending. It is important to note this program's payments are distinct from payments made for dispensing, with VBPP payments being provided to pharmacies directly by Wellmark.

Each of the 4 target chronic conditions had a metric related to medication adherence. This led pharmacies participating in the VBPP to address medication nonadherence using a range of actions such as tracking adherence in the dispensing system, medication synchronization, adherence packaging, and interventions to address reasons for nonadherence. ${ }^{17}$ Over the past 20 years, helping patients address medication nonadherence has become a key component of enhanced pharmacy services. This growth has been driven, in part, by a recognition of the costs of nonadherence and by the inclusion by CMS of medication adherence metrics in their Medicare Part D Star Rating Program (eg, proportion of days covered for oral diabetes medications) ${ }^{18}$ So, having adherence-related metrics throughout the VBPP provided the participating pharmacists with a familiar target and approach-working with beneficiaries to address medication nonadherence. Although it was not done in such a systematic manner as in the Pennsylvania Project, the VBPP adds further evidence community pharmacists can improve health outcomes when monitoring medication therapy, educating patients about their medications, and helping patients address medication nonadherence. Both projects showed a significantly lower level of health 


\begin{tabular}{|c|c|c|c|}
\hline Parameter & Estimate & SE & $\begin{array}{c}\text { Wald } \\
\text { chi-square }\end{array}$ \\
\hline Non-VBPP pharmacy & 0.0208 & 0.0350 & 0.35 \\
\hline Wellmark ACO indicator (not in ACO) & 0.1430 & 0.0230 & $38.38^{d}$ \\
\hline Urban location (no) & 0.2190 & 0.0227 & $92.56^{d}$ \\
\hline Gender (female) & -0.0483 & 0.0220 & $4.83^{b}$ \\
\hline Number of unique drugs & 0.0292 & 0.0029 & $102.08^{d}$ \\
\hline Number of unique prescriptions & 0.0701 & 0.0054 & $167.58^{d}$ \\
\hline Clinical Risk Group3M-ED risk weight value & 0.1300 & 0.0040 & $1,070.07^{d}$ \\
\hline Coronary artery disease indicator (no) & -0.2170 & 0.0371 & $34.07^{d}$ \\
\hline Depression indicator (no) & -0.2870 & 0.0236 & $148.32^{\mathrm{d}}$ \\
\hline Diabetes indicator (no) & 0.0228 & 0.0298 & 0.59 \\
\hline Asthma indicator (no) & -0.2710 & 0.0308 & $77.51^{d}$ \\
\hline Wellmark PPOindicator (yes in PPO) & -0.1940 & 0.0214 & $82.51^{d}$ \\
\hline Intercept & -2.4200 & 0.0723 & $1,122.10^{d}$ \\
\hline \multicolumn{4}{|c|}{ 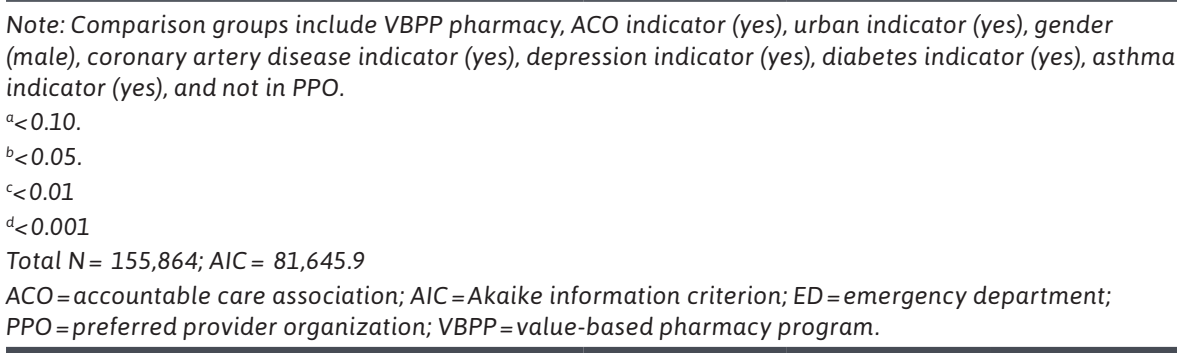 } \\
\hline
\end{tabular}

care costs in relation to comparison groups.

Though not specifically measured, the pharmacists in the VBPP pharmacies reported performing activities that can reduce total cost of care and limit health care waste. One example was the work done to improve monitoring of chronic medication therapy through the collection of blood pressure and hemoglobin A1c levels. This work improves care delivery in that providers could adjust therapy confidently if they were made aware of the effectiveness and safety effects of medication therapy by pharmacists' monitoring. Because patients visit pharmacies much more often than they do clinics, pharmacists monitoring medication therapy can alert prescribers about failure to reach research is needed to better identify pharmacist actions that most clearly limit waste. ${ }^{19}$

Results support that a key to a successful value-based payment program for pharmacies is to position them to use their clinical skills and knowledge to affect total costs of care. Some community pharmacists are capable of collaborating with prescribers and patients to manage medication therapy, intervening with patients to improve medication adherence, identifying a need for and administering immunizations, identifying and resolving adverse drug effects and coaching patients on lifestyle choices. ${ }^{17}$ Many of the pharmacies that participated in the VBPP provide such services and were free to use their clinical judgment in determining which patients would benefit from which services. Because this was a capitated valuebased payment program, the payer had less risk for questionable services than under a fee-for-service approach. Here the pharmacists were incentivized to perform quality care and affect total cost of care while controlling their own costs by matching service delivery to patient need.

Many of the participating pharmacies are members of a Community Pharmacy Enhanced Services Network (CPESN). These CPESNs, which are clinically integrated networks, have emerged recently in most states as progressive pharmacies seeking to transform their practices and receive reimbursement for enhanced services. ${ }^{20,21}$ These pharmacies have changed their operations to regularly monitor the medication therapy of their patients with chronic conditions and coordinate with broader care teams to get the best outcomes from their patients' medications. Because not all pharmacies are ready to deliver enhanced services, payers interested in pursuing a pharmacy program like the VBPP may benefit 


\section{FIGURE 2 Longitudinal Comparison of Total Costs of Care VBPP Group vs Non-VBPP Group}

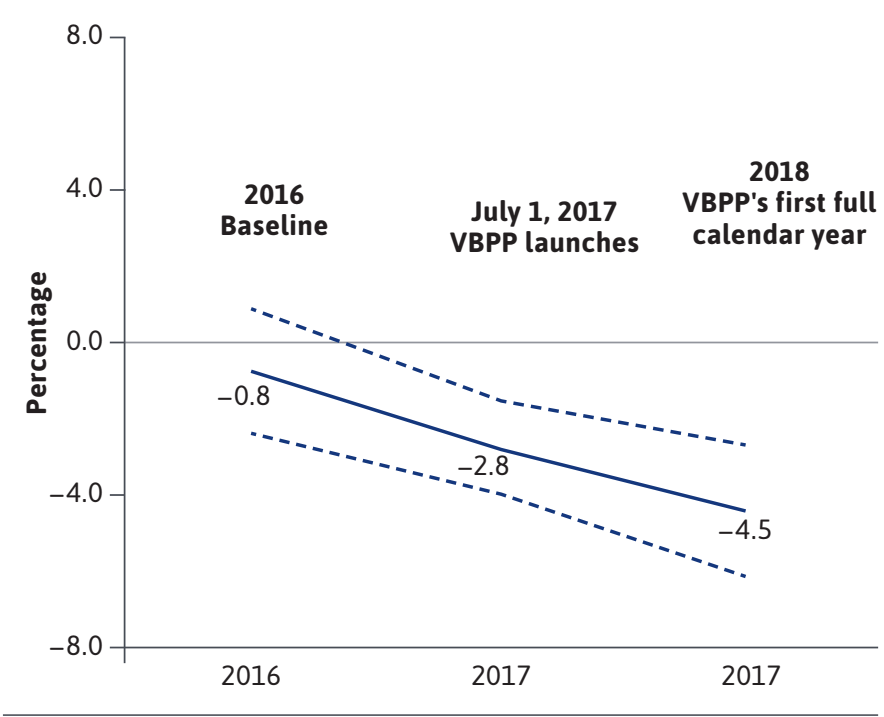

Note: Dotted lines show $95 \%$ confidence intervals.

VBPP $=$ value-based pharmacy program.

from collaborating with a CPESN in their area. CPESN USA, an umbrella organization of the state-level networks, lists over 40 CPESNs in more than 40 states (www.cpesn.com). As with the VBPP, such pharmacies may provide a strong core of pharmacies for a value-based payment program.

Many health plans could use a value-based payment model for pharmacies to complement their ACO. The health plan in this study designed the VBPP so the key metrics of the total cost of care, ED visits, and admissions were shared with its ACO. In the study findings, beneficiaries who were attributed to an ACO and VBPP had lower costs than those who were in only one or neither. A characteristic of the VBPP is that the pharmacists monitor medication therapy more closely and interact with providers to alert them when safety issues or ineffectiveness appear to be present. Such discussions between practitioners support timely adjustments in therapy and can clarify treatment goals for patients. The improved coordination of medication therapy is likely to benefit both the providers in an ACO and pharmacies in a value-based payment program.

\section{LIMITATIONS}

A limitation of these analyses is that beneficiaries were not randomized as to whether they would receive the services associated with the VBPP, potentially creating a self-selection bias. The statistical analyses attempted to control for potential differences between the VBPP group and the comparison group. Also, beneficiaries were attributed to the pharmacy from which they received the most prescriptions dispensed. While most beneficiaries went to only 1 pharmacy, others had prescriptions dispensed by multiple pharmacies. It is possible the actions of the other pharmacies could have affected the results of these analyses. However, in the absence of incentives from the VBPP, it would not be expected that nonparticipating pharmacies would deliver extra services to such patients. Also, although we collected some data about what activities the pharmacists were performing, we do not know which actions were driving the cost savings. Some of the results may have come from actions related to improving medication adherence, since such activities have been associated with health care cost savings and have been reported by these pharmacies.12,22 Other actions are more anecdotal, such as calling patients a few weeks after they start a new antidepressant medication or coaching patients on accessing the ED. The participating pharmacies typically flagged their VBPP-attributed beneficiaries in their dispensing systems, which allowed them to attend to them more closely at the time of dispensing and perform additional services to address target conditions or medications of interest. However, the precise information on the frequency and duration of these interactions was unavailable for these analyses. Further study is needed to learn more about which actions contributed most to the lowered total cost of care.

\section{FUTURE RESEARCH}

The VBPP was implemented in 73 community pharmacies serving about 40,000 beneficiaries in 2 states. While these analyses provide a useful first look at such a value-based payment model for pharmacies, more research is needed using a larger pharmacy network with more beneficiaries. Such research could help us learn more about the attributes of high-performing pharmacies under a value-based payment model. Similarly, results suggest that insurers are likely to benefit from pursuing value-based payment models that position pharmacists to utilize their clinical skills to identify and address their patients' needs and affect total costs of care. This study showed that pharmacists can respond when given adequate incentives and transparent performance metrics. In addition, although these results apply most directly to commercial insurers, such value-based programs could be implemented for other beneficiary groups, including Medicare and Medicaid beneficiaries, who often rely on medication therapy to manage multiple chronic conditions. For example, research with Medicaid-managed care organizations using a program like 
the VBPP could inform policymakers about the benefits of these programs for Medicaid beneficiaries.

\section{Conclusions}

With the growing need for solutions to improve quality of care while reducing health care costs and waste, a valuebased payment program that provides capitated payments to community pharmacies offering enhanced clinical services significantly reduced total cost of care in a commercial population with 1 or more chronic conditions. Future work with this promising model is encouraged.

\section{DISCLOSURES}

No external funding was obtained to support this study. Devolder and Heggen are employed by Wellmark, Inc. Doucette is supported by the Deborah K. Veale Professorship in Healthcare Policy at the University of Iowa. The authors have no other potential conflicts of interest to disclose.

\section{REFERENCES}

1. Shrank WH, Rogstad TL, Parekh N. Waste in the US health care system: estimated costs and potential for savings. JAMA. 2019;322(15):1501-09. doi:10.1001/ jama.2019.13978

2. Washington Health Alliance. First, do no harm. Washington Health Alliance. Published February 2018. Accessed August 31, 2020. https://www.wacommunitycheckup.org/media/47186/ first-do-no-harm-feb-2018.pdf

3. Gill E, Dykes PC, Rudin RS, Storm M, McGrath K, Bates DW. Technologyfacilitated care coordination in rural areas: what is needed? Int J Med Inform. 2020;137:104102. doi:10.1016/j. ijmedinf.2020.104102
4. Ozavci G, Bucknall T, Woodward-Kron R, et al. A systematic review of older patients' experiences and perceptions of communication about managing medication across transitions of care. Res Social Adm Pharm. 2020;17(2):273-91. doi:10.1016/j.sapharm.2020.03.023

5. Casalino LP, Gans D, Weber R, et al. US physician practices spend more than $\$ 15.4$ billion annually to report quality measures. Health Aff (Millwood). 2016;35(3):401-06. doi:10.1377/ hlthaff.2015.1258

6. Gee E, Spiro T. Excess administrative costs burden the US health care system. Center for American Progress. Published April 8, 2019. Accessed April 20, 2020. https://www.americanprogress.org/issues/healthcare/ reports/2019/04/08/468302/excessadministrative-costs-burden-u-s-healthcare-system

7. Centers for Medicare \& Medicaid Services. 2019 merit-based incentive payment system (MIPS) quality performance category fact sheet. Accessed March 10, 2020. https:// qpp-cm-prod-content.s3.amazonaws. com/uploads/350/2019\%20MIPS\%20 Quality\%20Performance\%20Category\%20 Factsheet.pdf

8. Nelson L. Lessons from Medicare's demonstration projects on disease management, care coordination, and value-based payment. Congressional Budget Office Working Paper 2012-02. Published January 2012. Accessed March 10, 2020. https://www.cbo.gov/ publication $/ 42860$

9. Centers for Medicare \& Medicaid Services. 2018 quality performance category scoring for alternative payment models. Accessed March 10, 2020. https:// qpp-cm-prod-content.s3.amazonaws. com/uploads/131/2018\%20MIPS\%20 APM\%20Quality\%20Scoring\%20 Guide_2018\%2004\%2020.pdf
10. Pikoulas T, McKee J, Jackson C, Trygstad T, Mahan A, Lancaster M. Community care of North Carolina a statewide initiative for innovative pharmacy practice with a behavioral health focus. Mental Health Clinician. 2014;4(6):271-75. https://doi.org/10.9740/ mhc.n207202

11. Bonner L. As pay for performance grows, health plans work with pharmacies. Pharmacy Today. 2016;22(3):50-53.

12. Pringle JL, Boyer A, Conklin MH, McCullough JW, Aldridge A. The Pennsylvania project: pharmacist intervention improved medication adherence and reduced health care costs. Health Aff (Millwood). 2014;33(8):1444-52. doi:10.1377/ hlthaff.2013.1398

13. Doucette WR, McDonough RP, Herald F, Goedken A, Funk J, Deninger MJ. Pharmacy performance while providing continuous medication monitoring. $J$ Am Pharm Assoc (2003). 2017;57(6):692-97. doi:10.1016/j.japh.2017.07.006

14. Gibson TB, Wang S, Kelly E, et al. A value-based insurance design program at a large company boosted medication adherence for employees with chronic illnesses. Health Aff (Millwood). 2011;30(1):109-17. doi:10.1377/ hlthaff.2010.0510

15. Maciejewski ML, Wansink D, Lindquist JH, Parker JC, Farley JF. Valuebased insurance design program in North Carolina increased medication adherence but was not cost neutral. Health Aff (Millwood). 2014;33(2):300-08. doi:10.1377/ hlthaff.2013.0260

16. Biniek JF, Hargraves J. 2018 health care cost and utilization report. Health Care Cost Institute. Accessed April 24, 2020. https://healthcostinstitute.org/images/ pdfs/HCCI_2018_Health_Care_Cost_ and_Utilization_Report.pdf

17. Al-Khatib A, Andreski M, Pudlo A, Doucette WR. An evaluation of community pharmacies' actions under value-based payment. J Am Pharm Assoc (2003). 2020. In press. doi:10.1016/j. japh.2020.06.014 
18. Centers for Medicare \& Medicaid Services. Medicare 2020 part C \& D star tatings technical notes. Updated 10 01, 2019. Accessed April 24, 2020. https://www.cms.gov/Medicare/ Prescription-Drug-Coverage/ PrescriptionDrugCovGenIn/Downloads/ Star-Ratings-Technical-NotesOct-10-2019.pdf

19. American Society of Health-System Pharmacists. Choosing wisely: five things physicians and patients should question. Choosing Wisely. Published June 1, 2017. Accessed April 24, 2020.https:// www.choosingwisely.org/wp-content/ uploads/2017/05/ASHP-Choosing-WiselyList.pdf
20. Hall C. Pharmacists: partner with physicians on chronic care to better manage patients. Pharmacy Times. Published October 8, 2018. Accessed April 1, 2020. https://www.pharmacytimes.com/conferences/ncpa-2018/ pharmacists-partner-with-physicians-onchronic-care-to-better-manage-patients

21. Hoey BD. Pharmacy payment model needs to be simplified. Chain Drug Review. 2019. Accessed April 1, 2020. https://www.chaindrugreview.com/ pharmacy-payment-model-needs-to-besimplified/
22. Braithwaite S, Shirkhorshidian I, Jones K, Johnsrud M. The Role of medication adherence in the US healthcare system. Avalere. Published June 2013. Accessed April 24, 2020. http://citeseerx. ist.psu.edu/viewdoc/download?doi=10.1.1. $\underline{357.6179 \& \text { rep }=\text { rep } 1 \& \text { type }=\text { pdf }}$ 